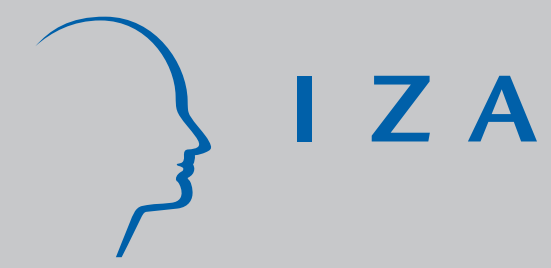

IZA DP No. 398

An Econometric Analysis of the Mental-Health Effects of Major Events in the Life of Elderly Individuals

Maarten Lindeboom

France Portrait

Gerard J . van den Berg

November 2001 


\title{
An Econometric Analysis of the Mental- Health Effects of Major Events in the Life of Elderly Individuals
}

\author{
Maarten Lindeboom \\ Department of Economics, Free University Amsterdam, Tinbergen Institute and IZA, Bonn
}

France Portrait

Department of Economics and Faculty of Medicine, Free University Amsterdam

Gerard J. van den Berg

Department of Economics, Free University Amsterdam, Tinbergen Institute, CEPR, IFAU-Uppsala and IZA, Bonn

Discussion Paper No. 398

November 2001

\author{
IZA \\ P.O. Box 7240 \\ D-53072 Bonn \\ Germany \\ Tel.: +49-228-3894-0 \\ Fax: +49-228-3894-210 \\ Email: iza@iza.org
}

This Discussion Paper is issued within the framework of IZA's research area The Future of Work. Any opinions expressed here are those of the author(s) and not those of the institute. Research disseminated by IZA may include views on policy, but the institute itself takes no institutional policy positions.

The Institute for the Study of Labor (IZA) in Bonn is a local and virtual international research center and a place of communication between science, politics and business. IZA is an independent, nonprofit limited liability company (Gesellschaft mit beschränkter Haftung) supported by the Deutsche Post AG. The center is associated with the University of Bonn and offers a stimulating research environment through its research networks, research support, and visitors and doctoral programs. IZA engages in (i) original and internationally competitive research in all fields of labor economics, (ii) development of policy concepts, and (iii) dissemination of research results and concepts to the interested public. The current research program deals with (1) mobility and flexibility of labor markets, (2) internationalization of labor markets and European integration, (3) the welfare state and labor markets, (4) labor markets in transition, (5) the future of work, (6) project evaluation and (7) general labor economics.

IZA Discussion Papers often represent preliminary work and are circulated to encourage discussion. Citation of such a paper should account for its provisional character. 
IZA Discussion Paper No. 398

November 2001

\title{
ABSTRACT
}

\section{An Econometric Analysis of the Mental-Health Effects of Major Events in the Life of Elderly Individuals*}

\begin{abstract}
Major events in the life of an elderly individual, such as retirement, a significant decrease in income, death of the spouse, disability, and a move to a nursing home, may affect the mental health status of the individual. For example, the individual may enter a prolonged depression. We investigate this using unique longitudinal panel data that track labor market behavior, health status, and major life events, over time. To deal with endogenous aspects of these events we apply fixed effects estimation methods. We find some strikingly large effects of certain events on the occurrence of depression. We show that the results are of importance for the design of health care and labor market policy towards the elderly.
\end{abstract}

\section{JEL Classification: $\quad$ C5, I1}

Keywords: Death, retirement, income loss, disease, depression, health indicators, widowhood, care, panel data, endogeneity, fixed effects

\author{
Maarten Lindeboom \\ Department of Economics \\ Free University Amsterdam \\ De Boelelaan 1105 \\ 1081 HV Amsterdam \\ The Netherlands \\ Tel.: +31204446033 \\ Email: mlindeboom@econ.vu.nl
}

\footnotetext{
We acknowledge valuable comments and suggestions by Jaap Abbring, Rob Alessie, and Dorly Deeg. The Longitudinal Aging Study Amsterdam (LASA) kindly allowed us to use their data. The LASA study is mainly financed by a long-term grant from the Netherlands Ministry of Health, Welfare and Sports.
} 


\section{Introduction}

Individual health at advanced ages is determined by endowed genetic factors, by consumption, smoking, drinking, and exercising, by health care, and by so-called life events. With the latter term we mean major events in the life of the individual that occur more or less suddenly. Elderly individuals are relatively likely to face certain types of life events, like retirement, a significant decrease in income, death of the spouse, disability, onset of a serious illness, and a move to a nursing home. These may have a particularly large effect on the mental health status of the individual, and this is what we investigate in the present paper.

Let us examine some of these life events in more detail. The onset or relapse of a life-threatening or disabling disease may affect mental health. A "forced move" to an institution for the elderly due to a need for assistance and care is likely to result in a further deterioration of mental or physical health as well. The death of the spouse and the concurrent changes in the lives of widowed persons have regularly been shown as most important sources of psychosocial stress - a factor associated with increased morbidity and mortality $(13,17,24,27)$. For instance, significant increases in rates of (chronic) depression or anxiety have been observed after the death of the partner. Bereavement or work loss may also induce a reduction of the number of social contacts, so that the individual may experience feelings of loneliness. Presumably, the death or a serious illness of a close friend or kin will affect health status in a comparable way. Additionally, there is evidence that widowhood is often associated with more poverty (21), which in turn may affect health. Labor market status and changes in labor market status at the working ages (below 65 in the Netherlands) may affect mental health as well. There may be a direct effect, for instance because inactivity associated with retirement may affect an individual's mental health. Moreover, retirement is in general associated with a drop in income and as such an indirect effect on health may be expected.

The demand for mental health care and the expenditures on mental health care are directly determined by the distribution of mental health in the population. As a consequence, insight into the factors that determine mental health is desirable. Major life events are easily observable to health care workers. That means that they are potentially very useful "red flags" that may trigger action by the health care workers. If a life event has a large effect on mental health then it is useful for health care workers to focus on the occurrence of such events, and to undertake action in the form of intensified mental health care if such events are observed. 
To look at this from another point of view, the availability of a partner, children, or a close person, may be crucial in determining the demand for professional long-term care services. Informal care - the non-organized care provided from within the social network of the individual - is an essential supplement or substitute to professional long-term care in most countries. The death or illness of a major informal caretaker may result in an increase in costly professional care firstly to replace the care provided by the deceased person and secondly to meet the increase in needs of the survivor if bereavement induces a decline in health status. As such, insight in the effect of bereavement on mental health is important to monitor future needs in long-term care services of the older population.

Additionally, major changes in labor market policies towards the elderly have recently been suggested and implemented in most OECD countries, in light of the growing concern for reduced labor force participation rates of the elderly and foreseen changes in the demographics in these countries. Any policy aimed at the labor market positions of the elderly should be aware of the social costs or benefits associated with work or non-work states, such as unemployment, disability insurance, or early retirement schemes, and with the concurrent changes in incomes. Finally, from the early 1980s onwards, the Dutch government has strongly encouraged the older population to maintain an independent lifestyle for as long as possible. This study allows us to assess the effect on mental health - after controlling for health status - of moving to an institution for the elderly. As such, the present paper brings to light the consequences on mental health of the older population of the ongoing policy of substitution of extramural for intramural long-term care. In sum, this study is of interest to economic policy and health care policy.

Empirical studies on the relation between life events and health have to address the potential endogeneity of life events. The occurrence of a life event may be affected by factors that also have a direct effect on health. If such factors are not observed, and the analysis does not take account of their presence, then the results may be biased. For example, an individual with a genetic predisposition towards mental illness may move into the disability program before retirement, and he may also frequently display periods of mental illness. In that case the data show a positive relation between the occurrence of a transition into disability on the one hand, and the occurrence of mental illness on the other. However, this should not necessarily be taken as evidence of a causal effect from disability to mental illness.

As far as we know, studies on the relationships between morbidity and partner status generally assume that the stochastic processes underlying morbidity of 
both spouses are independent. Nevertheless it seems plausible that the probabilities of lifetime partners of suffering from health disorders are associated through unobserved or not well-documented individual characteristics (e.g. they may have similar health-related behaviors, eating patterns, material circumstances, or life history). In that case, results based on studies that ignore this possible correlation may be biased. Similarly, it is often found that higher incomes are associated with better health, even if one controls for education and other measures of ability (see, for instance, 2, 9, 10). It is, however, difficult to assess to what extent the estimates found in these studies represent the true causal effects of income on health. There may be a direct effect of income on health (individuals with higher income may have better access to health care services, or may be better informed about the hazards of specific health related behavior). Alternatively, health problems may affect the individual's productivity. Finally, there may be unobservables such as life style variables, risk aversion, and frailty that govern both health status and income. Often, studies that assess the impact of income on health either assume that income is strictly exogenous to health or rely on untestable instruments. ${ }^{1}$

Impairment in mental health may prevent people from working, and unobservables associated with health and work (for instance previous investments in income and health) may relate both. The endogeneity between health and work has been acknowledged in the labor supply literature, but still surprisingly little work exists in this area. Exceptions include Bazzoli (1), Stern (26), Bound et al. (3), Kerkhofs and Lindeboom (16) and Lindeboom and Kerkhofs (19).

The present paper adds to the different strands of literature mentioned above, by dealing with the possible endogeneity of life events. We rely on a framework where the simultaneous nature of the life events and of mental health is determined by time-invariant individual factors. In addition, we use longitudinal data in which the timing and sequence of life events and health deterioration are observed. This enables us to observe which occurs first and to control for the role of joint determinants. Concerning the latter, we use so-called fixed-effect estimation methods for panel data. Advantages of fixed-effect methods are $(i)$ we do not need to rely on the specification of a model explaining occurrence of life events, and $(i i)$ we do not need instrumental variables that affect life events but do not have a direct effect on mental health. Obviously, such instruments are hard if not impossible to find. By first-differencing the observations on mental health

\footnotetext{
${ }^{1}$ Exceptions include the studies by Lindahl (18) and Case (4), who use monetary lottery prizes and unanticipated changes in the South-African pension system, respectively, as sources of exogenous variation in income.
} 
indicators over time, we get rid of the unobserved individual heterogeneity and, consequently, of the possible correlation between mental health and life events. The first-difference equations can be correctly estimated using simple OLS methods. The method assumes that the occurrence of life events is independent of the remaining time-varying residual term in the regression. It is therefore important to allow for a broad range of variables accounting for shocks occurring during the sample period.

We use a unique panel data set of Dutch elderly individuals that includes a wide range of socio-demographic variables as well as detailed information on health and the occurrence of major life events that older persons are often confronted with. For instance, death of partner, parents, siblings or offspring of respondents are observed during the sample period, as well as changes in labor market states, moves, major shocks in income, and the onset of chronic diseases. Of relevance for our analyses is that we observe a significant fraction of respondents to die during the sample frame. We check whether the attrition is non-random and conclude that it is. We subsequently develop and apply a way to deal with this attrition problem.

The remainder of this paper is organized as follows. Section 2 describes the data used in the analyses. Section 3 presents the statistical model and includes a discussion of alternative methods to estimate the model in the case that the data are subject to attrition. Section 4 presents and discusses the results and Section 5 concludes.

\section{The data}

\subsection{Description and summary statistics}

The data from the Longitudinal Aging Study Amsterdam (LASA) (7, 8) follow a representative sample of the Dutch institutionalized and non-institutionalized population of individuals aged 55-85 over an extended period of time. Currently three waves are available (the 1992-1993 wave, the 1995-1996 wave, and the 1998-1999 wave). It should be noted that no refreshment samples are drawn at wave II and wave III. A specification of the non-response in the LASA data is given in Table 1. 
Table 1: Specification of the non-Response in the LASA DATA

\begin{tabular}{lrrr}
\hline & Wave I & Wave II & Wave III \\
\hline Number of individuals & 2,925 & 2,204 & 1,717 \\
Deceased & - & 417 & 344 \\
Short interviews & 182 & 98 & 157 \\
Refusals & - & 145 & 125 \\
Interviews by telephone & - & 243 & 202 \\
\hline
\end{tabular}

Because of data limitations, respondents with a short interview or a proxy interview as well as respondents who refuse to participate in the second or third wave are excluded from our analysis. We realize that the resulting sample after exclusion of these respondents - may be selective with respect to (mental) health. In previous work, we compare health status of respondents with a complete interview with the one of respondents that refuse to participate in the second wave (see 23). Individuals who remain in the sample are in general slightly more healthy than their counterparts. Respondents were submitted either to a complete interview or to a short interview according to their ability to sustain a lengthy interview. Therefore it can be expected that respondents with a short interview are generally less healthy than the ones of the rest of the sample. On the other hand, there is evidence that individuals with an interview by telephone are healthier than the remaining respondents (see 8). Therefore, the possible selectivity of the resulting sample - i.e. after exclusion of respondents with a short interview, an interview by telephone, or who refuse to participate in the second or third wave - compared to the initial sample may not be too serious. Table 2 gives information on the reduced sample.

Table 2: Attrition due to mortality in the Reduced SAmple

\begin{tabular}{lrrr}
\hline & Wave I & Wave II & Wave III \\
& & & \\
\hline Number of individuals & 2,253 & 1,894 & 1,284 \\
Deceased & - & 359 & 251 \\
\hline
\end{tabular}

The data are individual data and not household data, which means that relatively little information on the other members of the household is available in the data set. Information has been collected on physical, emotional, cognitive, and social functioning. Each of these components is assessed by a broad set of subjective and objective measures. In addition, information is collected on characteristics that are expected to be of influence for one or more components of 
functioning mentioned above. Of interest for our study is that these characteristics include information on major life events. Table 3 presents sample means and/or frequencies for each of the three waves on a set of relevant variables.

Table 3 also includes means of tests and indicators of health. We use the MMSE (see 11) and the CES-D (see 25) variable as dependent variables in our analyses. The Mini Mental State Examination (MMSE) is a widely used method for assessing cognitive status. It provides a total score that places the individual on a scale of cognitive functioning. The lower the score, the higher the cognitive impairment. The variable ranges between 0 and 30 and usually a cut-off point of 23/24 is used to indicate cognitive impairment. The Center for Epidemiological Studies Depression Scale (CES-D) is used to measure emotional functioning of the elderly. The total score ranges from 0 to 60 and respondents with scores higher than 16 display clinically relevant symptoms of depression.

Physical functioning is measured by a self-report indicator on mobility in daily life and by a performance test of physical ability. The first variable assesses the ability of the respondent to walk up and down 15 steps of a staircase without stopping, to use public or private transport and to cut one's own toenails. The score takes on value 0 when all three activities are performed without difficulties, one, two, or three when respectively one, two, or three activities are performed with difficulties. The performance test measures in seconds the time needed to take on and off a cardigan, the time needed to walk three meters back and forth along a rope, and the time needed to get up from a kitchen chair five times with arms folded (8).

Finally, the presence of chronic diseases is assessed by asking the participants whether they have or have had any of the following diseases: chronic obstructive pulmonary diseases (COPD), heart diseases, peripheral artery diseases, stroke, diabetes, arthritis, and cancer.

From Table 3 it is clear that most changes in the means of the dependent variables are small, although the score of the CES-D variable is somewhat higher at the third wave. Figures 1 and 2 show that the entire distribution of the scores does not change much across the different waves (waves I, II, and II are relabeled as B, C, and D, respectively, in the figures). This may indicate that sample attrition is not selective with respect to the variables of interest. We check this more closely in the next subsection. The cut-off points for MMSE and CES-D are 23 and 16 respectively and hence the figures show that only a small fraction of our sample can be called cognitively impaired or depressed.

The development of the distribution of the self assessed functional limitation 
Table 3: MeAn / Frequency of RELEvant VARIAbles

\begin{tabular}{|c|c|c|c|c|}
\hline & Score & $\begin{array}{r}\text { Wave } 92 / 93 \\
(\%)\end{array}$ & $\begin{array}{r}\text { Wave } 95 / 96 \\
(\%) \\
\end{array}$ & $\begin{array}{r}\text { Wave } 98 / 99 \\
(\%) \\
\end{array}$ \\
\hline DECEASED & & - & 18.9 & 16.3 \\
\hline \multicolumn{5}{|l|}{ HEALth VARIABLES } \\
\hline MMSE (test on cognitive ability) & mean & 26.8 & 26.7 & 26.8 \\
\hline CES-D (test on depressive feelings) & mean & 8.0 & 8.0 & 8.6 \\
\hline Functional limitations & no difficulty & 58.5 & 49.7 & 44.6 \\
\hline \multirow[t]{3}{*}{ (based on three items) } & one with difficulty & 19.1 & 22.9 & 22.8 \\
\hline & two with difficulty & 11.7 & 13.4 & 16.4 \\
\hline & three with difficulty & 10.8 & 14.0 & 16.2 \\
\hline \multicolumn{5}{|l|}{ Performance test: } \\
\hline \multirow[t]{3}{*}{ Time cardigan } & under median & 53.1 & 50.0 & 53.4 \\
\hline & above median & 43.5 & 46.5 & 42.6 \\
\hline & not done ${ }^{1}$ & 3.4 & 3.5 & 4.0 \\
\hline \multirow[t]{3}{*}{ Time walk } & under median & 49.2 & 51.4 & 55.1 \\
\hline & above median & 47.7 & 45.0 & 41.2 \\
\hline & not done ${ }^{1}$ & 3.1 & 3.6 & 3.7 \\
\hline \multirow[t]{3}{*}{ Time chair } & under median & 55.2 & 49.9 & 47.1 \\
\hline & above median & 36.6 & 39.6 & 42.8 \\
\hline & not done ${ }^{1}$ & 8.2 & 10.5 & 10.1 \\
\hline \multicolumn{5}{|l|}{ Chronic diseases: } \\
\hline Respiratory diseases (COPD) & Yes & 11.2 & 12.4 & 14.9 \\
\hline Heart diseases & Yes & 19.5 & 21.9 & 26.4 \\
\hline Peripheral artery disease & Yes & 9.7 & 11.6 & 11.5 \\
\hline Diabetes & Yes & 7.8 & 7.2 & 8.9 \\
\hline Stroke & Yes & 4.6 & 6.3 & 6.9 \\
\hline Arthritis & Yes & 32.5 & 42.7 & 48.2 \\
\hline Cancer & Yes & 8.5 & 11.0 & 12.9 \\
\hline \multicolumn{5}{|l|}{ DEMOGRAPHICS } \\
\hline Age & mean & 69.9 & 71.8 & 73.7 \\
\hline Gender & female & 50.0 & 50.2 & 52.4 \\
\hline \multirow[t]{4}{*}{ Marital status } & never married & 5.6 & 5.3 & 5.1 \\
\hline & married & 64.7 & 57.9 & 55.3 \\
\hline & divorced & 5.0 & 5.4 & 5.5 \\
\hline & widowed & 24.7 & 31.3 & 34.1 \\
\hline Institutionalized & Yes & 3.8 & 4.6 & 5.1 \\
\hline \multirow[t]{3}{*}{ Education } & elementary & 41.0 & 40.0 & 39.4 \\
\hline & intermediate & 43.6 & 45.5 & 45.8 \\
\hline & high & 15.3 & 14.3 & 14.9 \\
\hline \multirow[t]{5}{*}{ Monthly netto income } & missing & 16.1 & 18.9 & 20.9 \\
\hline & $<1.500$ & 18.8 & 13.1 & 8.6 \\
\hline & $1.501-3.000$ & 42.6 & 40.5 & 39.2 \\
\hline & $3.001-4.500$ & 14.8 & 17.6 & 18.9 \\
\hline & $>4.501$ & 7.7 & 10.0 & 12.4 \\
\hline Paid job & Yes & 13.0 & 8.4 & 5.9 \\
\hline Disability Insurance Recipients & Yes & 7.1 & 1.1 & 0.6 \\
\hline \multirow[t]{2}{*}{ Early Retirement } & partly & 0.8 & 0.5 & 0.8 \\
\hline & completely & 5.9 & 2.1 & 1.5 \\
\hline Degree of urbanization & low & 13.3 & 13.9 & 13.2 \\
\hline \multirow[t]{2}{*}{ (only observed at wave I) } & medium & 27.8 & 28.0 & 28.1 \\
\hline & high & 58.9 & 58.1 & 58.7 \\
\hline SAMPLE SIZE & & 2.253 & 1.894 & 1.284 \\
\hline
\end{tabular}

${ }^{1}$ : The respondents were not able to perform the test. 
Figure 1: Distribution of MMSE scores at waves $1=\mathrm{B}, 2=\mathrm{C}$, and $3=\mathrm{D}$

MMSE score, Waves B, C, en D

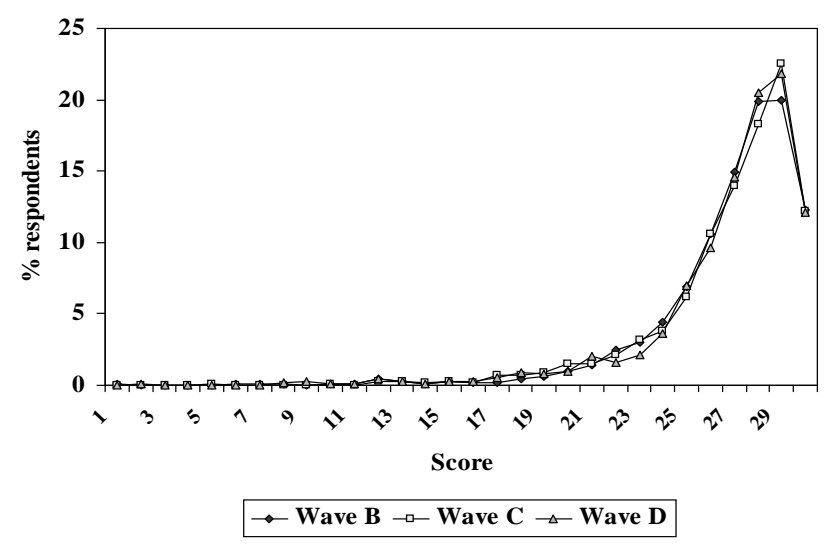

Figure 2: Distribution of CES-D scores at waves $1=\mathrm{B}, 2=\mathrm{C}$, and $3=\mathrm{D}$

\section{CES-D score, Waves B, C, en D}

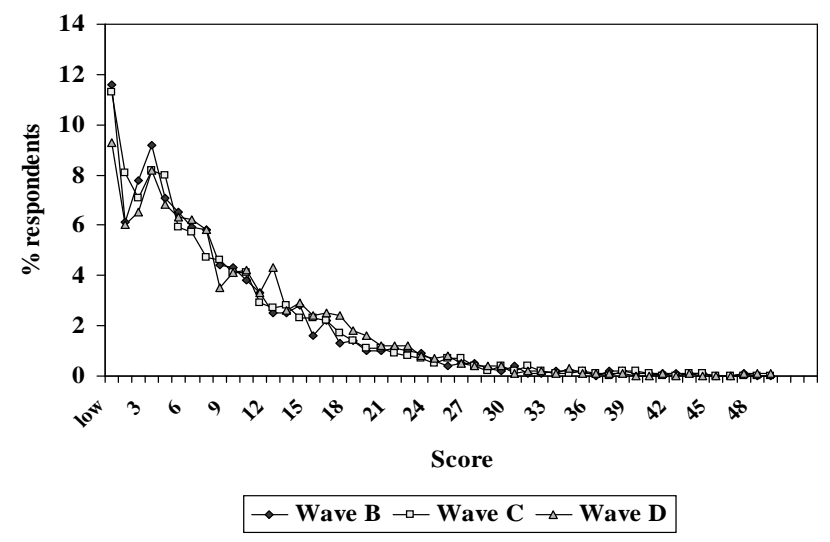


variable indicates that physical health deteriorates over time. About $27 \%$ of the respondents die during the observation period and it is therefore somewhat remarkable to still find such marked declines in physical health. This result can be refined by a look at the figures with respect to the objective test on physical ability. The figures on the cardigan test and on the chair test show a slight deterioration of the physical ability over time; the figures on the walking test are more ambiguous and could demonstrate some improvement of the mobility over time. At least, the results on the performance test do not validate the results based on the examination of the figures regarding subjective physical health. Therefore it is difficult to give a definite conclusion on the evolution of physical health status over the sample period. It should be mentioned that, in the interest of conciseness, percentages above and under the median as well as of respondents who were not able to perform the test only are reported in Table 3. In the empirical part of the paper we use the recorded time in seconds as outcome of the three items of the performance test. The respondents who were not able to perform the test are arbitrarily given a score equal to twice the maximum time required to perform the test.

Note that the sample ages with almost 4 years during the 6 to 7 years that we follow them. In the empirical part of the study, age is recorded in years minus 55. As expected, the fraction of females, widowers, and people living in an institution increases over time. The examination of figures regarding education and income indicates that, regardless of the aging of our sample, the average socioeconomic status increases over time. This is not completely surprising as lower educated individuals and individuals with lower incomes are known to have a higher probability of dying than their counterparts (see, for instance, 15). It is important to notice the high numbers of missings with respect to income. Altogether, about 500 respondents refuse to mention their income in at least one wave. As a consequence, in the empirical part of the study, we decided to exclude the variable measuring income from our analyses. Henceforth, information on (changes in) income is captured by the binary variable: "do you have experience serious financial problems since the last interview?". The fraction of individuals with a paid job, participating in a Disability Insurance program or in an Early Retirement program decreases over time, this arising primarily from the aging of our sample. Unfortunately, because of limitations of the data, we were not able to exactly identify whether or not an individual could be considered as being unemployed.

Table 4 presents frequencies of life events occurring between successive waves. More than $6 \%$ of the respondents lose their partner between wave I and II. This 
is about $10 \%$ of the relevant group of married individuals (6.4\%/0.647). Due to aging of our sample, this fraction reduces to 3.1 between wave II and wave III. Furthermore, regarding changes in incomes, the onset of severe financial problems is observed for a small, yet non-negligible, fraction of respondents. Finally, with respect to chronic diseases, arthritis and heart diseases are the most commonly observed chronic conditions and we also observe their onset most frequently. A substantial fraction of the respondents loses at least a brother or a sister during the observation period. Illness of partner and relatives is also a common phenomenon. It remains to be seen how all these factors affect the evolution of an individual's mental health, as measured by changes in the MMSE and CES-D scores.

Table 5 pictures the changes observed in the scores measuring cognitive impairment and (chronic) depression during the period intervening successive waves.

Table 5 shows that although the cognitive health of a substantial proportion of the respondents decreases over time (42.9\% between I and II, and $40.5 \%$ between II and III), 32.6\% (between I and II) and 35\% (between II and III) of our respondents experience an improvement of their cognitive status. This may be partly explained by a "learning" effect, i.e. in the second and third wave the respondents know how the test develops and can therefore pay more attention to specific parts of it. With respect to the CES-D test, examination of the figures also shows that emotional health varies considerably over time. Still, a larger fraction of respondents experience a decrease of the CES-D test over time.

The longitudinal nature of the data will help us in assessing the causal effect from possibly endogenous variables such as changes in labor market status and other life events on CES-D and MMSE tests. The longitudinal nature of our data also introduces the problem of sample attrition (see Table 1), a problem, that given the nature of our endogenous variable - mental health - has to be dealt with. Below we discuss this issue and its consequences for our statistical model.

\subsection{A test on non-random attrition}

Table 2 indicates that about $27 \%$ of the initially selected respondents die between wave I and III. This is of particular relevance in the context of our problem, where we are interested in the (dynamics) of mental health. Morbidity and mortality are clearly related and is moreover conceivable that there exist factors that are usually not observed (such as an individuals proneness to engage in risky activities) that relate both. As a result, an initially random sample may end up as a selective sample where the relatively healthy individuals are overrepresented - with conse- 
Table 4: FREQUENCY OF LIFE EVENTS

\begin{tabular}{|c|c|c|c|}
\hline & Score & $\begin{array}{r}\text { Between } \\
92 / 93 \text { and } 95 / 96\end{array}$ & $\begin{array}{r}\text { Between } \\
95 / 96 \text { and } 98 / 99\end{array}$ \\
\hline DeCEASED & & 18.9 & 16.3 \\
\hline \multicolumn{4}{|l|}{ DEMOGRAPHICS } \\
\hline \multirow[t]{2}{*}{ Change partner status } & Widowed & 6.4 & 3.1 \\
\hline & Separated & 1.7 & 1.3 \\
\hline Move to an independent dwelling & Yes & 10.9 & 9.8 \\
\hline Move to an institution & Yes & 1.8 & 1.5 \\
\hline Severe financial problems & Yes & 2.9 & 1.6 \\
\hline Loss of paid job & Yes & 5.2 & 2.4 \\
\hline New Disability Insurance Recipients & Yes & 0.6 & 0.3 \\
\hline \multirow[t]{2}{*}{ New "early" pensioners } & Partly & 0.7 & 0.9 \\
\hline & Completely & 3.1 & 1.3 \\
\hline \multicolumn{4}{|l|}{ Chronic DISEASES 1,2} \\
\hline Respiratory diseases (COPD) & Onset & 3.0 & 4.0 \\
\hline Heart diseases & $\begin{array}{l}\text { Onset or } \\
\text { Relapse }\end{array}$ & 6.1 & 4.6 \\
\hline Peripheral artery diseases & Onset & 3.1 & 2.1 \\
\hline Diabetes & Onset & 2.0 & 2.7 \\
\hline Stroke & $\begin{array}{l}\text { Onset or } \\
\text { Relapse }\end{array}$ & 3.5 & 2.7 \\
\hline Arthritis & Onset & 14.2 & 10.6 \\
\hline Cancer & $\begin{array}{l}\text { Onset or } \\
\text { Relapse }\end{array}$ & 3.9 & 3.9 \\
\hline \multicolumn{4}{|l|}{ OTHERS } \\
\hline Surgery $^{3}$ & Yes & 7.2 & 10.0 \\
\hline Death parent & Yes & 6.2 & 3.4 \\
\hline Death brother or sister & Yes & 23.8 & 23.0 \\
\hline Death children & Yes & 1.7 & 1.9 \\
\hline Death grandchildren & Yes & 1.4 & 1.0 \\
\hline Illness partner & Yes & 13.7 & 12.5 \\
\hline Illness relatives & Yes & 45.3 & 44.5 \\
\hline Severe conflicts with others & Yes & 9.3 & 8.7 \\
\hline Victim of crimes & Yes & 1.6 & 2.4 \\
\hline
\end{tabular}

${ }^{1}$ Onset was recorded when the respondent mentioned at wave $(t-1)$ no presence of a specific disease and he or she is observed to suffer from this specific diseases at wave $(t)$.

${ }^{2}$ Relapse was recorded when the respondent mentioned one or several myocardial infarctions (for heart diseases), strokes (for stroke), or tumors (for cancer) since the previous interview.

3 The variable "Surgery" was given a score 1 when the respondent has had a surgery for at least one of the diseases mentioned above. 
Table 5: Observed changes in Variables that measure mental health

\begin{tabular}{lccccccccc}
\hline $\begin{array}{l}\text { Changes in score } \\
\text { (in \%) }\end{array}$ & $>-5$ & {$[-5,-2[$} & {$[-2,-1[$} & -1 & 0 & 1 & ] $1,2]$ & ] $2,5]$ & $<5$ \\
\hline & & & & & & & & & \\
MMSE & & & & & & & & & \\
$\quad$ - betw. I \& II & 1.9 & 9.7 & 11.3 & 20.0 & 24.5 & 16.7 & 9.8 & 5.7 & 0.4 \\
$\quad$ - betw. II \& III & 2.1 & 9.1 & 10.4 & 18.9 & 24.6 & 19.4 & 9.0 & 6.1 & 0.5 \\
& & & & & & & & & \\
CES-D & & & & & & & & & \\
$\quad$ - betw. I \& II & 12.5 & 13.9 & 7.2 & 7.6 & 11.7 & 8.1 & 6.8 & 16.7 & 15.2 \\
- betw. II \& III & 9.1 & 8.7 & 5.6 & 7.6 & 10.9 & 8.4 & 7.9 & 13.8 & 15.4 \\
\hline
\end{tabular}

quences for the measurement of the effect of life events on health. Note, however, that mental impairment may not necessarily be associated to higher mortality rates, as long as it is not directly associated to other impairments that reduce life expectancy. There is however, some evidence that this might indeed be the case (see for instance 13, 27, 17, 24).

To proceed, we perform some simple checks to see if attrition is selective. As a first check we examine the distribution of mental health as observed in wave I and see if there exists an association with future attrition/death. This boils down to a regression of, for instance, CES-D on a range of personal characteristics, a measure of physical health and an indicator for future attrition ${ }^{2}$. This informal test gives an indication of the relevance of attrition, in particular when attrition is governed by determinants that are themselves invariant over time. One can judge this by the significance of the attrition indicator, as well as by stability of the other coefficients of the model, under alternative specifications (see 28).

Results of specifications with CES-D and MMSE as measures for mental health reveal that the attrition dummy is significant in a specification of CES$\mathrm{D} / \mathrm{MMSE}$ on a range of exogenous variables (gender, age, education level, marital status, and degree of urbanization of the municipality where the respondent lives) and an attrition dummy. The coefficient of the attrition dummy in the CES-D specification is negative, which means that "stayers" in the sample have, ceteris paribus, a better emotional health than the deceased individual. In the MMSE specification, the dummy coefficient is negative which boils down to a better cognitive health of survivors compared to the deceased respondents. The attrition dummy is not significant if one adds a measure for physical health to the equation. Note however, that this regression is invalid if unobservables affect both

\footnotetext{
${ }^{2}$ Results regarding regressions with respect to attrition are available on request from the authors.
} 
mental and physical health. Moreover, there are some changes in the coefficients of the CES-D and MMSE regressions if one excludes the attrition dummy variable. One may conclude from these exercises that attrition is most likely to be selective with respect to mental health and that ignoring this most likely will have consequences for the coefficients of interest. Consequently, we have to deal with this attrition problem in the empirical analysis.

\section{The empirical model specifications}

\subsection{Regression equations with fixed effects}

Consider the following equation relating mental health $H_{i t}$ to a range of socioeconomic and demographic variables $X_{i t}$, a set of life event variables $Z_{i t}$, a timeinvariant individual-specific effect $d_{i}$, and an idiosyncratic shock $u_{i t}$,

$$
H_{i t}=X_{i t}^{\prime} \beta+Z_{i t}^{\prime} \gamma+d_{i}+u_{i t}
$$

Here, $H_{i t}, X_{i t}$ and $Z_{i t}$ are observed, while $d_{i}$ and $u_{i t}$ are unobserved. We assume that $X_{i t}$ and $Z_{i t}$ are orthogonal to $u_{i t}$ (we return to this assumption below). The elements of $\gamma$ capture the effect of the life events $Z_{i t}$ on mental health $H_{i t}$, so they are the parameters of interest. Obviously, OLS estimation of $\gamma$ is complicated by the fact that $d_{i}$ is unobserved, so that $X_{i t}$ and $Z_{i t}$ may not be orthogonal to the residual term $d_{i}+u_{i t}$. For instance, as in the emerging economic literature on the relationship between socio-economic status and health, labor market status and/or income (which both influence $Z_{i t}$ ) may well be related to $d_{i}$. Recall the discussion on endogeneity in Section 1.

Common ways to deal with this endogeneity (or simultaneity) problem include (i) extending model (1) with equations for the elements of $Z_{i t}$, (ii) specifying the correlation between $d_{i}$ and $Z_{i t}$ directly (see for instance Mundlak (22) or Chamberlain (5) ), and (iii) use a fixed-effect approach. Extending equation (1) with separate equations for $Z_{i t}$ may not be convenient in this case as $Z_{i t}$ includes a relatively large number of elements. Moreover, this approach requires valid instruments in order to identify the true causal effect from $Z_{i t}$ on $H_{i t}$. That is, the equations for $Z_{i t}$ need to contain explanatory variables that are not in $X_{i t}$. Approaches as suggested by Mundlak and Chamberlain are less cumbersome to estimate. Moreover, valid instruments are still required, and the results may be sensitive to the specification chosen for the correlation between $Z_{i t}$ and $d_{i}$. 
Since we have longitudinal panel data at our disposal, we may apply a fixedeffect approach (see e.g. 14). This approach does not rely on functional-form or exclusion restrictions, which is a marked advantage.

The fixed-effect approach is based on first differences of equation (1) over time. Let $\Delta$ denote the first difference operator, so e.g. $\Delta X_{i t}:=X_{i t}-X_{i, t-1}$. We have

$$
\Delta H_{i t}=\left(\Delta X_{i t}\right)^{\prime} \beta+\left(\Delta Z_{i t}\right)^{\prime} \gamma+\Delta u_{i t}
$$

Note that in case $Z_{i t}=1$ corresponds to a more or less unique and irreversible event (like death of the partner), $Z_{i t}=1$ is equivalent to $\Delta Z_{i t}=1$.

Clearly, in equation (2), the time-invariant individual effects is eliminated, and the regressors are orthogonal to the residual term in (2). One could in principle rely on simple ordinary least squares estimation of this equation. This would ignore the correlation between $\Delta u_{i t}$ and $\Delta u_{i, t-1}$. Note that the correlation disappears if the following specification is assumed:

$$
u_{i t}=u_{i, t-1}+\eta_{i t}
$$

where $\eta_{i t}$ is i.i.d. normally distributed with mean zero and variance $\sigma^{2}$. This specification accounts for persistence of unobserved shocks across periods. In this case,

$$
\Delta u_{i t}=\eta_{i t}
$$

and equation (2) can be correctly estimated by simple OLS techniques.

One possible drawback of the fixed effect approach is that the time-invariant regressors (i.e. sex, education, degree of urbanization where the respondent lives) drop out of the model. However, in the present paper, we are interested in assessing the effect of life events - which by definition vary over time - on mental health.

Now let us return to the requirement that $Z_{i t}$ is orthogonal to $u_{i t}$. Most applications of fixed-effect methods tacitly assume this. This assumption may be violated if there are unobserved transitory shocks that affect mental health and that affect or are affected by $Z_{i t}$. For instance, the sudden onset of a lifethreatening disease like cancer may have direct instantaneous effects on mental health and on labor supply and income (e.g. through medical consumption). 
Similar arguments may apply in the case that the partner, a parent, or a child of the individual becomes very ill. Likewise, the onset of a disease, a surgery, or a move in an institution for the elderly could affect mental and physical health simultaneously. These shocks may affect or be affected by $X_{i t}, Z_{i t}$ and $d_{i}$. To deal with this, the shocks have to be included as explanatory variables. It is therefore of importance to include as many time-varying determinants of mental health as possible. We are in the fortunate position to have access to data that observe events like moves, surgeries, the onset of life threatening chronic conditions, such as cancer, heart problems, stroke etc, and whether or not deaths or sudden shocks to the health of partner or close relatives have taken place. Of course, these are also "life events" in their own right. In sum, it is of importance to include as many life events as possible as explanatory variables, and our data are well suited to this, as they record an unusually large variety of them. As a result, in the absence of non-random attrition, equation (2) is correctly estimated by using simple OLS methods.

\subsection{Non-random attrition in the model framework}

However, as noted in Subsection 2.2, about 25\% of our sample is observed to die between waves I and III and this is likely to be selective. We need to correct for this in the context of our fixed effects model. Suppose that attrition is governed by a latent index $M_{i}^{*}$ : if it exceeds zero then the respondent $i$ participates in all three waves of the survey. In most practical situations one specifies a model for $M_{i}^{*}$ and estimates this along with equation (1). Alternatively one could employ a two-stage procedure, where the model for $M_{i}^{*}$ is used to construct conditional moments of $d_{i}$ to correct for selectivity. This two-stage procedure produces an interesting result in the case that we condition on survival in a fixed number of waves. Let us start with the condition that the respondents survive in all waves of our panel survey and suppose that this is governed by:

$$
M_{i}^{*}=W_{i 0}^{\prime} \alpha+v_{i}
$$

where $W_{i 0}$ is a set of strictly exogenous explanatory variables observed at the initial wave and $v_{i}$ is an individual stochastic component. In line with much of the research in this area (Hausman and Wise (12), Ridder (1993) and Gottschalk and Moffitt (1996), we assume conveniently that there exists an association between $v_{i}$ and $d_{i}$, rather than between $v_{i}$ and $u_{i t}$, for some or all $t$. In this case, conditioning on presence at all waves implies for the mean of our health variable $H_{i t}$ that: 


$$
\begin{aligned}
E\left[H_{i t} \mid M_{i}^{*}>0\right] & =X_{i t}^{\prime} \beta+Z_{i t}^{\prime} \gamma+E\left[d_{i} \mid M_{i}^{*}>0\right] \\
& =X_{i t}^{\prime} \beta+Z_{i t}^{\prime} \gamma+f\left(W_{i 0}^{\prime} \alpha\right)
\end{aligned}
$$

where $f\left(W_{i 0}^{\prime} \alpha\right)$ is an arbitrary function for the conditional mean $E\left[d_{i} \mid M_{i} *>0\right]$, that boils down to the (standard) inverse of Mill's ratio under the assumption of joint normality of $d_{i}$ and $v_{i}$. Of interest for our purposes is that $f\left(W_{i 0}^{\prime} \alpha\right)$ varies over individuals but not over time. Therefore, differenced regressions of mental health $H_{i t}$ only depend on differences in $X_{i t}, Z_{i t}$ and $u_{i t}$, as in equation (2). The above reasoning justifies the use of the fixed-effect specification in models using panel data sets that are subject to non-random attrition.

So far we conditioned on all waves, but it may be clear that we need not to restrict ourselves to samples of individuals that survive in all waves. Using similar arguments one could construct other similar subsamples, where we condition on presence in all but the last wave, all but the last two waves etc. Given the model assumptions, this will only affect $E\left[d_{i} \mid M_{i}^{*}>0\right]=f\left(W_{i 0}^{\prime} \alpha\right)$ in equation (3), but, as these cancel out while differencing, it will not affect the estimates of $\beta$ and $\gamma$. Estimation remains therefore very simple: select all individuals who remain in the sample for at least two waves and estimate a first-difference equation, hereby controlling for any correlation that might exist between the time persistent components $v_{i}$ and $d_{i}$ in our model. Apart from its simplicity, the procedure proposed is attractive, as estimates of $\beta$ and $\gamma$ do not depend on exclusion restrictions or (equivalently) instruments, usually imposed in a random effects framework.

The procedure outlined above fails in the case that, apart from a correlation between $v_{i}$ and $d_{i}$, also a correlation between $v_{i}$ and $u_{i t}$ exists. In this case the relevant conditional expectation in equation (3) equals $E\left[d_{i}+u_{i t} \mid M_{i}^{*}>0\right]$, which will generally vary over time. As a consequence, differencing the data may not eliminate all correlation between the included regressors and the stochastic component due to non-random attrition. A pragmatic way to deal with this is to include a dummy for each specific subsample of respondents participating in a range of consecutive interviews. In our case, where we have access to three waves, this means that we include those individuals in the sample who remain for two waves and those who remain for three waves and to add a dummy to the specification identifying the three wave participants. This variable is aimed to capture all relevant correlations between observables and unobservables that remain after differencing the health equation. 


\section{The results}

Tables 6 and 7 below report the results with respect to cognitive health (MMSE) and depression (CES-D) respectively. Low scores of the MMSE variables are associated with low cognitive skills. The reverse holds for CES-D: high scores are associated with greater feelings of depression.

A quick glance at Tables 6 and 7 reveals that life events have a larger effect on emotional status than on cognitive health, at least in the (relatively) short run. At the most, we follow the respondents during 7 years. Firstly, it is reasonable to assume that not all cognitive damage will show up immediately after occurrence of life events and that deterioration of cognitive health will take more time to arise than feelings of depression. There is for instance evidence that spousal bereavement increases the rate of depression of the survivors already in the first year of the widowhood and that the effect decreases after approximately four years. During the same period of time (i.e four years), no effect of bereavement on cognitive skills could be demonstrated (see for instance 6, 20). Possibly, in the current study, the sample period is too short to be able to witness all transitions in cognitive health due to major life events. Secondly, genetic factors or physiological dysfunctions (like inadequate cellular development), rather than environmental conditions (like life events), may play a more important part in cognitive decline than in the occurrence of emotional disabilities.

With respect to health variables, onset of chronic diseases is found to have a less debilitating effect on mental health than increases in physical limitations (see performance test) and feelings of depression. ${ }^{3}$ We did not really expect a deterioration of cognitive health due to onset or relapse of chronic diseases, except for diseases that are directly related with cognition. We do observe a decrease - though not statistically significant - of the MMSE score for respondents that have recently experienced episodes of strokes. The deterioration of cognitive skills as a result of increases in physical and emotional disabilities may be explained by a lowering of social contacts: older individuals may stay at home more often (due to mobility impairment or lack of zest in life). This is likely to induce a reduction of intellectual stimuli and some cognitive apathy. An additional result of our analyses - which at a first glance may appear quite singular - is the strong

\footnotetext{
${ }^{3}$ The analyses reported in Tables 6 and 7 allow the change in the cognitive skill indicator to affect the change in the depression indicator and vice versa. Taken together, this creates an endogeneity problem in the regressions, which can be solved if at least one of these relations is known to be absent, so that the system of equations is recursive. However, the estimation results are insensitive with respect to whether we allow for these relations or not.
} 
Table 6: Results MMSE ( High COGNitive MENTAl State)

\begin{tabular}{|c|c|c|}
\hline Variables & Parameters & T-values \\
\hline Constant & 0.060 & 0.092 \\
\hline \multicolumn{3}{|l|}{ HEALTH VARIABLES } \\
\hline$\Delta($ CES-D $)$ & -0.010 & -1.825 \\
\hline$\Delta$ (Time cardigan $)$ & -0.002 & -2.001 \\
\hline$\Delta($ Time walk $)$ & 0.001 & 1.250 \\
\hline$\Delta$ (Time chair) & -0.001 & -1.955 \\
\hline$\Delta$ (Functional limitations $)$ & 0.045 & 0.888 \\
\hline$\Delta(\mathrm{COPD})$ & 0.091 & 0.445 \\
\hline$\Delta($ Heart diseases $)$ & -0.017 & -0.121 \\
\hline$\Delta$ (Peripheral artery diseases $)$ & 0.178 & 0.901 \\
\hline$\Delta$ (Diabetes $)$ & 0.111 & 0.451 \\
\hline$\Delta($ Stroke $)$ & -0.334 & -1.887 \\
\hline$\Delta$ (Arthritis) & 0.112 & 1.056 \\
\hline$\Delta$ (Cancer) & 0.057 & 0.302 \\
\hline Surgery & -0.073 & -0.473 \\
\hline \multicolumn{3}{|l|}{ DEMOGRAPHIC VARIABLES } \\
\hline$\Delta(\text { Age })^{a}$ & -0.074 & -0.352 \\
\hline$\Delta\left(\mathrm{Age}^{2}\right)$ & -0.006 & -6.783 \\
\hline Widowed & 0.060 & 0.368 \\
\hline Separated & 0.437 & 1.571 \\
\hline Move to an independent dwelling & 0.088 & 0.727 \\
\hline Move to an institution & -1.069 & -3.581 \\
\hline Severe financial problems & 0.144 & 0.583 \\
\hline Loss of paid job & 0.164 & 1.048 \\
\hline New Disability Insurance Recipient & 0.260 & 0.468 \\
\hline New "early" pensioner & -0.091 & -1.326 \\
\hline \multicolumn{3}{|l|}{ OTHERS } \\
\hline Death parents & -0.308 & -1.789 \\
\hline Death brothers and sisters & -0.034 & -0.386 \\
\hline Death children & -0.335 & -1.233 \\
\hline Death grandchildren & -0.199 & -0.593 \\
\hline Illness partner & 0.395 & 3.579 \\
\hline Illness relatives & 0.043 & 0.580 \\
\hline Severe conflicts with others & -0.069 & -0.532 \\
\hline Victim of crimes & -0.133 & -0.635 \\
\hline \multicolumn{3}{|l|}{ Dummies } \\
\hline Wave dummy & 0.348 & 2.221 \\
\hline Sample dummy & 0.089 & 1.117 \\
\hline
\end{tabular}


Table 7: Results CES-D ( HIGH DEPREssion)

\begin{tabular}{|c|c|c|}
\hline Variables & Parameters & T-values \\
\hline Constant & 0.355 & 0.175 \\
\hline \multicolumn{3}{|l|}{ Health Variables } \\
\hline$\Delta(\mathrm{MMSE})$ & -0.098 & -1.919 \\
\hline$\Delta$ (Time cardigan $)$ & 0.002 & 0.859 \\
\hline$\Delta$ (Time walk) & 0.002 & 1.227 \\
\hline$\Delta$ (Time chair) & 0.007 & 4.037 \\
\hline$\Delta$ (Functional limitations $)$ & 0.665 & 4.263 \\
\hline$\Delta(\mathrm{COPD})$ & -0.426 & -0.671 \\
\hline$\Delta$ (Heart diseases $)$ & 1.200 & 2.707 \\
\hline$\Delta$ (Peripheral artery diseases $)$ & -0.031 & -0.050 \\
\hline$\Delta$ (Diabetes $)$ & -1.291 & -1.691 \\
\hline$\Delta($ Stroke $)$ & 0.854 & 1.224 \\
\hline$\Delta$ (Arthritis) & 0.486 & 1.479 \\
\hline$\Delta$ (Cancer) & 0.891 & 1.509 \\
\hline Surgery & -0.986 & -2.049 \\
\hline \multicolumn{3}{|l|}{ DEMOGRAPHIC VARIABLES } \\
\hline$\Delta(\text { Age })^{a}$ & 0.032 & 0.049 \\
\hline$\Delta\left(\mathrm{Age}^{2}\right)$ & 0.002 & 0.771 \\
\hline Widowed & 3.417 & 6.730 \\
\hline Separated & -1.121 & -1.297 \\
\hline Move to an independent dwelling & 0.010 & 0.027 \\
\hline Move to an institution & 1.327 & 1.429 \\
\hline Severe financial problems & 1.306 & 1.707 \\
\hline Loss of paid job & 0.368 & 0.752 \\
\hline New Disability Insurance Recipient & 3.372 & 1.952 \\
\hline New "early" pensioner & -0.105 & -0.489 \\
\hline \multicolumn{3}{|l|}{ OTHERS } \\
\hline Death parents & -0.189 & -0.352 \\
\hline Death brothers and sisters & 0.062 & 0.224 \\
\hline Death children & 1.038 & 1.230 \\
\hline Death grandchildren & 2.803 & 2.692 \\
\hline Illness partner & 1.241 & 3.622 \\
\hline Illness relatives & 0.591 & 2.572 \\
\hline Severe conflicts with others & -0.005 & -0.014 \\
\hline Victim of crimes & -0.226 & -0.347 \\
\hline \multicolumn{3}{|l|}{ DUMMiES } \\
\hline Wave dummy & -1.505 & -3.089 \\
\hline Sample dummy & 0.848 & 3.417 \\
\hline
\end{tabular}


positive effect on cognitive health of the occurrence of a severe illness of the partner. In this case, the reverse reasoning may apply: the level of intellectual stimuli may increase as the respondent has to take care of his or her own life, but also of the one of his or her partner. She or he may have to deal with unusual situations and this may induce a sharpening of his or her cognitive abilities. Furthermore, there are some evidences - even not always highly conclusive - in the gerontological literature of a positive relationship between physical activity and cognitive health: older individuals who regularly exercise appear to have a better cognitive functioning than their counterparts. Consequently, variations in the level of physical activity may affect to some extent the cognitive skills of older individuals.

Regarding the effects of demographic characteristics on cognition, two major results are found. Firstly, there are strong age effects that imply declining cognitive abilities of people when they age. We opted for a quadratic specification of age. The quadratic variable appears to be strongly significant. This indicates that growing old with three years at for instance age 80 has a highly different effect on the evolution of cognition than at younger ages. Secondly, moving to an old people's home seemingly has a negative effect on cognitive abilities: new residents are found to be more cognitively impaired after than before their institutionalization - after prior adjustment for physical and emotional health. Therefore the deterioration of cognitive health can not be explained by an increase in physical limitation and emotional disability. The further deterioration of cognitive skills may primarily arise from the traumatic effect of changing environment and from the concurrent changes in daily life (e.g. diminution of social contacts, less physical exercise). Alternatively, this may be due to the fact that older institutionalized persons feel more dependent and rely more on the staff of old people's home to perform daily activities. Again, this boils down to a decrease in intellectual stimuli that may lead to some cognitive apathy. This result is somewhat offset by the fact that our analyses are not corrected for the exact timing of occurrence of life events. This information is not available in the data set. Therefore, it could be that the new resident has experienced a decline in cognitive ability prior to his or her institutionalization. Finally, it can be noted that changes in labor market status, in incomes (measured by the occurrence of serious financial problems), the death of a close person are not found to induce significant transitions in MMSE scores.

The effects of declines in physical health are found to be much higher on emotional health than on cognitive status. Firstly, the onset of life-threatening diseases like heart diseases and cancer - though the coefficient with respect to 
cancer is not significant - is responsible for higher feelings of depression. An increase in physical limitations (see performance test and self-report indicator on mobility) has a high significant negative effect on emotional health. Again emotional and cognitive health appear to be highly correlated since a drop in cognitive skills results in emergence or aggravation of depression. On the other hand, a positive effect of undergoing heart surgeries (like valves or dotter surgery, bypass, pacemaker), joint surgeries (like replacement of knee or hip joints), or surgical removals of tumors is observed. Presumably, the patient anticipates an improvement of his or her health, which positively affect his or her emotional status.

Not surprisingly, strong negative effects of conjugal bereavement, death of grandchildren, illness of the partner or of a close relative are found. The effects of the variables regarding the partner are larger than the other variables associated with bereavement, and also, remarkably, than other variables included in our study. Therefore, widowed individuals should be considered as a frail group; they are likely to suffer from serious emotional disorders after death of their spouse. The government should maybe focus on this group and offer bereaved persons psychological help immediately after the death of the close person to help them recover and retrieve zest in life. This may affect their future needs in formal long-term care services.

Strikingly a separation has a positive effect (though not statistically significant) on both aspects of mental health. It may be explained, on the one hand, by an increase in cognitive stimuli (singles have to take care of themselves), and, on the other hand, by some feelings of relief.

No negative effects of aging on the occurrence or aggravation of depression are found: the coefficient of the quadratic age variable, albeit positive, is not statistically significant. One may conclude that being depressed is not specifically associated with old ages, when controlling for changes in cognitive and physical health status.

Finally, examination of the coefficients with respect to income and work status shows that experiencing serious financial problem and participating in a Disability Insurance program significantly deteriorates emotional health.

Two dummies are also included in our models for mental health. First a dummy variable, denoted by "Wave dummy", is added to the matrix of regressors to control for time effects. Second a dummy variable, denoted by "Sample dummy", indicating whether a respondent participated in two or three waves is included as well. This variable is aimed to capture all relevant correlation between the observed regressors and the unobserved heterogeneity that remains after dif- 
ferencing the health equations (see last paragraph of Subsection 3.2). The "Wave" dummies are significant in both regressions, which indicates the presence of some time effects during the sample period. The "Sample dummy" is significant in the CES-D regression only. However there is very little difference between the coefficients of regressions with or without these dummies (see Tables A1 and A2 of the appendix).

\section{Conclusions}

This paper focuses on the effect on mental health of elderly persons of major life events like death or illnesses of their partner or of a close person, changes in work status (such as (early) retirement, or participation in Disability Insurance programs), the concurrent changes in income, or a move to a nursing home. Mental health is measured by two indicators: the Mini Mental State Examination (MMSE) and the Center for Epidemiological Studies Depression Scale (CES-D), two widely used tests in the fields of gerontology to assess the cognitive status and emotional status of older persons respectively.

The large majority of studies on this topic (or on the effect of one specific life event, like spousal bereavement or retirement) do not take into account the possible endogeneity between these life events and (mental) health. In the current paper, we rely on a framework where the simultaneous nature of the life events and of mental health is determined by time constant individual factors. Fixed effects methods are used to control for this kind of simultaneity. The resulting firstdifference model can be correctly estimated using simple OLS methods. In order to capture possible relations between life events and idiosyncratic time-varying residuals, our empirical specifications include a broad range of explanatory variables accounting for shocks occurring in the time between successive waves of the survey.

Major life events have a larger effect on depressive feelings than on cognitive skills. Concerning the effect of physical health on depression, we find particularly large significant effects for heart diseases. Signs of physical deterioration (accounted by lower scores on the performance test and the self-reported variables on physical mobility) also have an effect. On the other hand, undergoing surgery has a positive mood effect. Conjugal bereavement, death of grandchildren, illness of the partner or of a close relative are crucial triggers of (chronic) depression. Of these, not surprisingly, conjugal bereavement has the largest and most significant effect. Therefore, governments should consider widowed individuals as a frail group and undertake actions to help them retrieve zest in life. This may directly 
affect their future needs for costly formal long-term care services. It is interesting to point out that the second largest and most significant effect among the above concerns the death of a grandchild. This has a much stronger effect on depression than death of a child.

Declines in income and inflow into a Disability Insurance program significantly deteriorate emotional health. The former may be taken as an argument in favor of income support for elderly individuals after retirement or loss of a partner. Higher depressive feelings are not found after participation in Early Retirement schemes. This has some policy relevance, as it is presumable that employers use Disability Insurance programs to dismiss older workers.

Institutionalization has negative effects on both emotional well-being and cognitive abilities. Concerning cognitive abilities, we also find a negative effect of physical health deterioration. Furthermore, our study shows an increase of the rate of cognitive decline as people age. Changes in work status and serious financial problems do not have an effect on cognitive abilities. 


\section{References}

[1] Bazzoli G., The early retirement decision: New empirical evidence on the influence of health, Journal of Human Resources, 1985, 20: 214-234.

[2] Benzeval M., and K. Judge, Income and Health: the time dimension. Social Sciences and Medicine, May 2001, 52:1371-1390.

[3] Bound, J., M. Schoenbaum, T. R. Stinebrickner and T. Waidmann, Measuring the Effects of Health on Retirement Behavior, Labour Economics, 1999.

[4] Case, A., Does money protect Health Status? Evidence from South African pensions, NBER working paper 8495, 2001.

[5] G. Chamberlain Analysis of covariance with qualitative data, American Economic Review, Papers and Proceedings, 1980.

[6] Chou K., and I. Chi, Stressful events and depressive symptoms among old women and men: A longitudinal study, International Journal of Aging and Human Development, 2000, 51:275-293.

[7] Deeg, D.J.H. and M. Westendorp de Serière, Autonomy and well-being in the aging population, report from the Longitudinal Aging Study Amsterdam 1992-1993, VU University Press, Amsterdam 1994.

[8] Deeg, D.J.H., A. T. F. Beekman, D. M. W. Kriegsman and M. Westendorp de Serière, Autonomy and well-being in the aging population 2, report from the Longitudinal Aging Study Amsterdam 1992-1996, VU University Press, Amsterdam 1998.

[9] Ecob R., and G. Smith, Income and Health: what is the nature of the relationship?. Social Sciences and Medicine, March 1999, 48:693-705.

[10] Ettner S., New evidence on the relationship between income and health, Journal of Health Economics, 1996, 15, pp67-85.

[11] Folstein, M.F., S.E. Folstein, and P.R. McHugh Mini-mental state: a practical method for grading the cognitive state of patients for the clinician, Journal of Psychiatric Research, vol. 12, 1995.

[12] Hausman, J.A. and D. A. Wise, Attrition bias in experimental and panel data: the Gary income maintenance experiment, Econometrica (March 1979), Vol. 47.

[13] Holmes T., and R. Rahe, The social readjustment rating scale. Journal of Psychosomatic Research, 1967, 11:213-218. 
[14] Hsiao, C., Analysis of Panel Data, Cambridge University Press, 1986.

[15] Hurd, M.D., D. McFadden and A. Merrill Healthy, Wealthy, and Wise? Socioeconomic status, morbidity, and mortality among the elderly, Rand Corporation, Working paper, 1998.

[16] Kerkhofs, M.J.M. and M. Lindeboom, Age Related Health Dynamics and Changes in Labour Market Status, Health Economics, 1997.

[17] Lichtenstein P., M. Gatz, N. Pedersen, S. Berg, and G. McClearn, A co-twincontrol study of response to widowhood. Journal of Gerontology Series B, 1996, 51: 279-289.

[18] Lindahl M., Estimating the Effect of Income on Health using Monetary Lottery Prizes as Exogenous Source of Variation of Income. Mimeo University of Amsterdam, 2001.

[19] Lindeboom M., and M. Kerkhofs, Subjective Health Measures, Reporting Errors and the Endogenous Relationship between Health and Work. Mimeo Free University Amsterdam, 2001.

[20] Lindeboom M., F. Portrait, and G.J. van den Berg, Effect of Conjugal Bereavement on Health Status and Mortality, Mimeo Free University Amsterdam, 2001.

[21] McGarry K. End of life medical expenses and financial wellbeing of the surviving spouse. Working paper, UCL, 2001.

[22] Mundlak, Y. On the Pooling of Time Series and Cross Section Data, Econometrica, 1978, Vol. 46.

[23] Portrait, F., Long-term care services for the Dutch elderly - An investigation into the process of utilization. Thesis Free University, Amsterdam, 2000.

[24] Prigerson H., P. Maciejewski, and R. Rosenheck, The effects of marital dissolution and marital quality on health and health service use among women. Medical Care, Sept. 1999, 37:858-873.

[25] Radloff, L.S. The CES-D scale: a self-report depression scale for research in the general population, Appl Psych Meas, vol. 1, 1977.

[26] Stern, S. Measuring the effect of disability on labor force participation, Journal of Human Resources, 1989, 24:361-395.

[27] Stroebe W., and M. Stroebe, Bereavement and Health. New York: Cambridge University Press, 1987. 
[28] Van den Berg, G.J. and M. Lindeboom, Attrition in panel survey data and the estimation of multi-state labor market models, Journal of Human Resources, 1998, 33:458-478. 


\section{Table A1: Results MMSE Without WAVE AND time DUMMIES}

\begin{tabular}{|c|c|c|}
\hline Variables & Parameters & T-values \\
\hline Constant & 0.637 & 1.032 \\
\hline \multicolumn{3}{|l|}{ Health variables } \\
\hline$\Delta(\mathrm{CES}-\mathrm{D})$ & -0.010 & -1.969 \\
\hline$\Delta($ Time cardigan $)$ & -0.002 & -1.888 \\
\hline$\Delta($ Time walk $)$ & 0.001 & 1.190 \\
\hline$\Delta$ (Time chair) & -0.001 & -1.975 \\
\hline$\Delta$ (Functional limitations $)$ & 0.039 & 0.766 \\
\hline$\Delta(\mathrm{COPD})$ & 0.089 & 0.439 \\
\hline$\Delta($ Heart diseases $)$ & -0.032 & -0.224 \\
\hline$\Delta$ (Peripheral artery diseases $)$ & 0.153 & 0.772 \\
\hline$\Delta$ (Diabetes $)$ & 0.129 & 0.523 \\
\hline$\Delta($ Stroke $)$ & -0.355 & -1.781 \\
\hline$\Delta$ (Arthritis $)$ & 0.108 & 1.023 \\
\hline$\Delta$ (Cancer $)$ & 0.039 & 0.205 \\
\hline Surgery & -0.057 & -0.368 \\
\hline \multicolumn{3}{|l|}{ DEMOGRAPHIC VARIABLES } \\
\hline$\Delta(\text { Age })^{a}$ & -0.137 & -0.665 \\
\hline$\Delta\left(\mathrm{Age}^{2}\right)$ & -0.006 & -7.109 \\
\hline Widowed & 0.040 & 0.238 \\
\hline Separated & 0.445 & 1.600 \\
\hline Move to an independent dwelling & 0.096 & 0.798 \\
\hline Move to an institution & -1.161 & -3.921 \\
\hline Severe financial problems & 0.121 & 0.492 \\
\hline Loss of paid job & 0.171 & 1.089 \\
\hline New Disability Insurance Recipient & 0.250 & 0.449 \\
\hline New "early" pensioner & -0.086 & -1.245 \\
\hline \multicolumn{3}{|l|}{ OTHERS } \\
\hline Death parents & -0.320 & -1.857 \\
\hline Death brothers and sisters & -0.049 & -0.559 \\
\hline Death children & -0.346 & -1.274 \\
\hline Death grandchildren & -0.223 & -0.664 \\
\hline Illness partner & 0.398 & 3.609 \\
\hline Illness relatives & 0.052 & 0.703 \\
\hline Severe conflicts with others & -0.067 & -0.521 \\
\hline Victim of crimes & -0.154 & -0.735 \\
\hline
\end{tabular}


Table A2: Results CES-D without wave AND time Dummies

\begin{tabular}{|c|c|c|}
\hline Variables & Parameters & T-values \\
\hline Constant & 0.634 & 0.330 \\
\hline \multicolumn{3}{|l|}{ Health Variables } \\
\hline$\Delta(\mathrm{MMSE})$ & -0.101 & -1.968 \\
\hline$\Delta$ (Time cardigan $)$ & 0.003 & 0.993 \\
\hline$\Delta$ (Time walk) & 0.003 & 1.314 \\
\hline$\Delta$ (Time chair) & 0.007 & 3.895 \\
\hline$\Delta$ (Functional limitations $)$ & 0.684 & 4.379 \\
\hline$\Delta(\mathrm{COPD})$ & -0.298 & -0.468 \\
\hline$\Delta$ (Heart diseases $)$ & 1.183 & 2.664 \\
\hline$\Delta$ (Peripheral artery diseases $)$ & -0.056 & -0.091 \\
\hline$\Delta$ (Diabetes $)$ & -1.249 & -1.632 \\
\hline$\Delta($ Stroke $)$ & 0.796 & 1.139 \\
\hline$\Delta$ (Arthritis) & 0.408 & 1.240 \\
\hline$\Delta$ (Cancer) & 0.955 & 1.613 \\
\hline Surgery & -0.876 & -1.821 \\
\hline \multicolumn{3}{|l|}{ DEMOGRAPHIC VARIABLES } \\
\hline$\Delta(\text { Age })^{a}$ & -0.456 & -0.714 \\
\hline$\Delta\left(\mathrm{Age}^{2}\right)$ & 0.004 & 1.612 \\
\hline Widowed & 3.364 & 6.624 \\
\hline Separated & -1.137 & -1.312 \\
\hline Move to an independent dwelling & -0.023 & -0.062 \\
\hline Move to an institution & 1.652 & 1.889 \\
\hline Severe financial problems & 1.289 & 1.889 \\
\hline Loss of paid job & 0.437 & 0.893 \\
\hline New Disability Insurance Recipient & 3.446 & 1.991 \\
\hline New "early" pensioner & -0.067 & -0.318 \\
\hline \multicolumn{3}{|l|}{ OTHERS } \\
\hline Death parents & -0.255 & -0.475 \\
\hline Death brothers and sisters & 0.084 & 0.306 \\
\hline Death children & 1.085 & 1.282 \\
\hline Death grandchildren & 2.792 & 2.676 \\
\hline Illness partner & 1.210 & 3.523 \\
\hline Illness relatives & 0.566 & 2.458 \\
\hline Severe conflicts with others & 0.014 & 0.035 \\
\hline Victim of crimes & -0.254 & -0.389 \\
\hline
\end{tabular}




\section{IZA Discussion Papers}

No. Author(s)

384

385

386

387

388

389

390

391

392

393

394
D. Acemoglu

J.-S. Pischke

A. Ichino

R. T. Riphahn

J. Wagner

C. Schnabel

A. Kölling

C. Grund

D. Sliwka

L. Farrell

M. A. Shields

T. Beissinger

H. Egger

T. Beissinger

J. T. Addison

P. Teixeira

P. Tsakloglou

F. Papadopoulos

S. M. Fuess, Jr.

H. Gersbach

A. Schniewind

P. Manzini

C. Ponsatí

M. A. Shields

S. Wheatley Price

M. Frondel

C. M. Schmidt

M. Lindeboom

F. Portrait

G. J. van den Berg
Title

Area

Date

Minimum Wages and On-the-Job Training

11/01

The Effect of Employment Protection on Worker

$11 / 01$

Effort: A Comparison of Absenteeism During and After Probation

Threshold Values in German Labor Law and Job

3

Dynamics in Small Firms: The Case of the

Disability Law

The Impact of Wage Increases on Job

Satisfaction - Empirical Evidence and

Theoretical Implications

Child Expenditure: The Role of Working

3

$11 / 01$

Mothers, Lone Parents, Sibling Composition and Household Provision

Dynamic Wage Bargaining if Benefits are Tied to Individual Wages

The Impact of Labor Market Reforms on Capital

2

$11 / 01$

Flows, Wages and Unemployment

Employment Adjustment in Portugal: Evidence

$11 / 01$

from Aggregate and Firm Data

Identifying Population Groups at High Risk of

Social Exclusion: Evidence from the ECHP

Health

Evaluating Environmental Programs: The

6

Perspective of Modern Evaluation Research

An Econometric Analysis of the Mental-Health

$11 / 01$

Individuals 